\title{
ASSOCIAÇÃO ENTRE FORMIGAS (HYMENOPTERA:FORMICIDAE) E BACTÉRIAS PATOGÊNICAS EM CINCO HOSPITAIS DO MUNICÍPIO DE PELOTAS, RS
}

\author{
M.G. de Gonçalves ${ }^{1 *}$, A.E. Loeck ${ }^{1}$, E.J.E. e Silva ${ }^{1}$, W.P. da Silva ${ }^{2}$, \\ J.L.O. Rosado ${ }^{1}$, C.P. Bastos ${ }^{2}$, M.T. Bassani ${ }^{2}$
}

${ }^{1}$ Universidade Federal de Pelotas, Faculdade de Agronomia “Eliseu Maciel”, Departamento deFitossanidade, CP 354, CEP 96010-900, Pelotas, RS, Brasil. E-mail: michelmyrmex@gmail.com

\section{RESUMO}

O presente estudo teve por objetivo verificar a ocorrência de formigas em cinco hospitais do Município de Pelotas, analisar sua sazonalidade eidentificar bactérias patogênicas a elas associadas. Para tal, foram utilizadas duas iscas, uma contendo mel, açúcar e minhoca da espécie Eisenia foetida, e outra contendo sardinha da marca Coqueiro®. Ambas foram fixadas próximas aos rodapés de 19 a 21 setores de cada hospital (99 setores no total), e retiradas após $24 \mathrm{~h}$. O trabalho foi realizado durante as quatro estações de 2008 e 2009, totalizando 792 pontos amostrais. Foram encontradas sete espécies de formigas, distribuídas em 13 setores dentre os 99 amostrados (13,1\%). O verão foi a estação onde a maior porcentagem de amostras foi coletada, 57,6\%, sendo o menor número no inverno, 9,1\%. Foram coletadas assepticamente formigas de 28 pontos amostrais, sendo que 25 (89,3\%) apresentaram a ocorrência de bactérias patogênicas. As Enterobactérias estiveram presentes em 17 amostras, seguidas por Staphylococcus epidermidis e Staphylococcus saprophyticus em 13 e 9 amostras, respectivamente. Além disso, formigas de 20 pontos amostrais apresentaram mais de uma espécie bacteriana, com um máximo de cinco. Concluiu-se que as formigas são importantes carreadoras de bactérias patogênicas nos hospitais do município, e devem ser controladas a fim de se evitar maior ocorrência de infecções nosocomiais. Deve ser dada atenção ao controle na área externa dos hospitais, onde ocorre a nidificação da maioria dos espécimes coletados.

PALAVRAS-CHAVE: Infecções nosocomiais, formigas urbanas, formigas andarilhas, saúde pública.

\begin{abstract}
ASSOCIATION BETWEEN ANTS (HYMENOPTERA: FORMICIDAE) AND PATHOGENIC BACTERIA IN FIVE HOSPITALS IN THE CITY OF PELOTAS, STATE OF RIO GRANDE DO SUL, BRAZIL. The aim of the present study was to verify the occurrence of ants in 5 hospitals in the city of Pelotas, analyzing their seasonality and identifying associated pathogenic bacteria. For this, 2 baits were used, one containing honey, sugar and the earthworm Eisenia foetida, and another containing Coqueiro ${ }^{\circledR}$ brand sardines. Both baits were fixed close to the floor skirtings in 19 to 21 sectors in each hospital (99 sectors in total), and collected after $24 \mathrm{~h}$. The study was developed over the seasons of 2008 and 2009, for a total of 792 sampling points. A total of 7 ant species were found, distributed among 13 of the 99 sectors sampled (13.1\%). Summer was the season with the highest percentage of specimens gathered, $57.6 \%$, with the lowest number in the winter, $9.1 \%$. A total of 28 ant samples were aseptically collected, from which $25(89.3 \%)$ showed the occurrence of pathogenic bacteria. Enterobacteriaceae were found on 17 ant samples, followed by Staphylococcus epidermidis and Staphylococcus saprophyticus in 13 and 9 samples, respectively. Furthermore, ants from 20 sampling points showed the occurrence of more than one bacteria species, the maximum being 5. It was concluded that the ants are important carriers of pathogenic bacteria in hospitals, and must be controlled in order to avoid a higher occurrence of nosocomial infections. Moreover, attention must be given to the ant management in the external areas of the hospitals, where the colonies of most of the specimens collected are located.
\end{abstract}

KEY WORDS: Nosocomial infection, urban ants, tramp ants, public health.

${ }^{2}$ Universidade Federal de Pelotas, Faculdade de Agronomia "Eliseu Maciel”, Departamento de Ciência e Tecnologia Agroindustrial, Pelotas, RS, Brasil.

*Mestrando em Fitossanidade. 


\section{INTRODUÇÃO}

Dentre as aproximadamente 12.500 espécies de formigas (Hymenoptera: Formicidae) descritas (Agosti; Johnson, 2005), apenas 1\% delas são consideradas pragas (BuENo; CAMPOS-FARINHA, 1998). Neste grupo, encontram-se as comumente tratadas na literatura como formigas urbanas, que habitam casas, apartamentos, depósitos, fábricas e hospitais, sobrevivendo dealimentos ou lixo humano (CAMPOSFARINHA et al., 2002).

As formigas urbanas causam diversos tipos de incômodos, como reações alérgicas às ferroadas, danos em aparelhos eletroeletrônicos e contaminação de alimentos por possuírem o hábito de forragear sobre lixos e esgotos (BUENO; CAMPOS-FARINHA, 1998). Tais formigas compartilham algumas características em comum que as colocam no grupo das tramp ants ("formigas andarilhas"): associação com o homem, devido à disponibilidade de locais para nidificação e favorecimento para dispersão em longas distâncias; tendência em mudar o ninho constantemente de local; populações unicoloniais; alta agressividade interespecífica; poliginia; reprodução por budding ("brotamento" ou "fragmentação"); e tamanho pequeno (BUENO; CAMPOS-FARINHA, 1998).

No Município de Pelotas, Rio Grande do Sul, SiLVA; Loeck (1999) coletaram formigas presentes no ambiente urbano e verificaram que Brachymyrmex sp., Camponotus mus Roger, 1863, Linepithema humile (MAYr, 1868), Paratrechina fulva (MAYr, 1862), Pheidole spp., Solenopsis saevissima (Fr. SMIth, 1855) eWasmannia auropunctata (RoGER, 1863) foram as espécies mais frequentes no interior das residências.

Além dos incômodos ocasionados por sua presença em residências, as formigas são potenciais carreadoras de bactérias em ambientes hospitalares, inclusive resistentes a certos antibióticos (FowLER et al.; 1993; MOREIRA et al., 2005; RODOVALHO et al., 2007). Essa ocorrência é influenciada pela estrutura arquitetônica dos prédios, proximidadea residências, embalagens de medicamentos e transporte deninhos deformigas para o ambiente internojuntamente com vasos de flores, além dos alimentos depositados em locais inapropriados que funcionam como atrativo para os insetos se deslocarem para o interior das instalações (ZARZUELA et al., 2002).

A questão das infecções hospitalares tem despertado interesse devido à elevada mortalidade associada à bacteremias, inclusive as adquiridas após a internação (Quirino, 1997; GUILARDE et al., 2007). Dentre os agentes etiológicos encontrados em UTI's, as espécies da família Enterobacteriaceae são as mais frequentes, podendo ser responsáveis por um grande número de infecções (BlatT; MIRANDA, 2005). Quando achados clínicos estão relacionados a Estafilococos Coagulase-Negativos (ECN), o principal represen- tante deste grupo é Staphylococcus epidermidis, representando $60 \%$ a $80 \%$ dos isolados (KONEMAN et al., 2001). GUILARDE et al. (2007) encontraram $34,5 \%$ de letalidade associada à bacteremias em um hospital deGoiás. As bactérias isoladas com maior frequencia foram Staphylococcus spp., totalizando $44,1 \%$ de todas as bacteremias verdadeiras.

Dessa forma, os objetivos do estudo foram verificar a ocorrência de formigas em cinco hospitais do Município de Pelotas, analisar sua sazonalidade, identificar as espécies de bactérias associadas a elas e avaliar a potencialidade de risco à saúde pública nesses ambientes.

\section{MATERIAL E MÉTODOS}

\section{Caracterização do local de estudo}

Realizou-se uma coleta no mês final de cada estação do ano, sendo eles: março (verão), junho (outono), setembro (inverno) e dezembro (primavera), durante os anos de 2008 e 2009, em cinco hospitais do $\mathrm{Mu}-$ nicípio de Pelotas, situado na região fisiográfica da Encosta do Sudeste do Estado do Rio Grande do Sul, de coordenadas $31^{\circ} 45^{\prime} 43^{\prime \prime}$ Sule $52^{\circ} 21^{\prime} 00^{\prime \prime}$ Oeste, onde o clima é subtropical marítimo, considerado como Cfa segundo a classificação de Köppen. O verão é subúmido e as demais estações variam de úmido a superúmido (MORENO, 1961).

As épocas de coleta foram escolhidas visando respeitar o intervalo de três meses de duração de cada estação do ano e iniciaram em março de 2008. Os hospitais, por sua vez, foram escolhidos por apresentarem as edificações de maior porte entre as instituições do gênero no município. Os hospitais A, D e E são públicos, enquanto os hospitais B e C são privados. Quanto ao número de leitos, o hospital A possui 365, o B 214, o C 35, o D 239 e o E 102. Todos os hospitais apresentavam boas condições sanitárias e estruturais.

\section{Coleta de formigas}

As coletas foram realizadas com o auxílio de duas iscas atrativas. Uma delas, com consistência pastosa, preparada à base de açúcar, mel e minhoca Eisenia foetida (SAVGNY, 1862), escolhida por representar uma fonte de proteína animal de fácil obtenção. A minhoca, após ser mergulhada em água destilada para limpeza, foi desidratada em álcool $92 \%$ e liquidificada. A mistura foi preparada na proporção de uma parte de minhoca, uma parte de açúcar e duas partes de mel e aquecida até o ponto de fervura. Devido essa isca não ser atrativa a algumas espécies deformigas, fato observado durante a primeira coleta (verão), passou-se a utilizar também a isca consti- 
tuída por sardinha da marca Coqueiro®, enlatada com óleo de soja.

As iscas foram colocadas no interior de tubos BD Vacutainer ${ }^{\mathrm{TM}}$ de $5 \mathrm{~mL}$, sendo estes fixados com fita adesiva às paredes e rodapés, lado a lado, sendo recolhidos após 24h. Durante as coletas foram realizadas inspeções visuais no ambiente interno das instituições, tanto no momento da colocação das iscas quanto na retirada, objetivando a coleta de indivíduos que não foram atraídos pelas iscas. As formigas, uma vez localizadas na isca ou arredores, foram acompanhadas até o local de nidificação, de forma a avaliar se o ninho localizava-se no ambiente interno ou externo da edificação.

Os setores foram escolhidos priorizando-se as áreas de maior risco de contaminação hospitalar, além de locais de possível acesso de formigas ao interior das instalações (Tabela 1). Ao todo, 99 setores foram avaliados. Cada inspeção em um determinado setor, ao longo das oito coletas realizadas, foi considerada um ponto amostral, totalizando 792 pontos. Alguns setores não existiam em determinados hospitais, obrigando a escolha de pontos alternativos de interesse para o estudo. Em função da localização e dimensão dos hospitais não foram realizadas coletas na área externa.

O material coletado foi triado e identificado no Museu Entomológico “Ceslau Biezanko" (MECB) da Faculdade de Agronomia Eliseu Maciel (FAEM), Universidade Federal de Pelotas (UFPel), onde foi posteriormente depositado. A identificação foi realizada com auxílio das chaves sistemáticas de Trager (1991), Fernández (2003), Seifert (2003) e
WILSON (2003), além da comparação com as coleções do MECB e do Museu Zoológico da USP.

\section{Identificação de bactérias}

Para cada ponto onde verificou-se a ocorrência de formigas, foi coletada uma amosta contendo 10 espécimes com o uso de pinça esterilizada, visando o isolamento e identificação das espécies bacterianas associadas. Esses 10 indivíduos foram colocados em um tubo contendo meio de cultura infuso cérebro coração (BHI) esterilizado e levados ao Laboratório de Microbiologia de Alimentos da FAEM, UFPel, onde os tubos foram incubados a $35^{\circ} \mathrm{C}$, por um período de 48 horas.

Em todas as coletas foram realizadas análises para verificação da presença de Staphylococcus epidermidis, Staphylococcus hominis, Staphylococcus saprophyticus, Pseudomonas aeruginosa, Pseudomonas putida, Pseudomonas fluorescens e enterobactérias. A identificação e a diferenciação das três espécies de Staphylococcus foram realizadas através de características morfológicas em ágar Baird-Parker, produção de coagulase e de fosfatase e coloração de Gram. As espécies de Pseudomonas, identificadas em ágar pseudomonas, foram diferenciadas pela produção de oxidase, coloração de Gram, crescimento em Agar FLO e TECH, crescimento a $42^{\circ} \mathrm{C}$ e capacidade de hidrolisar a gelatina. As enterobactérias foram identificadas avaliando seu crescimento em VRBA, coloração de Gram e produção de oxidase (SNEATH et al., 1986; KONEMAN et al., 2001).

Tabela 1 - Setores avaliados em cinco hospitais do Município de Pelotas, RS, em 2008 e 2009.

\begin{tabular}{|c|c|c|c|c|c|}
\hline Setor & Hospital A & Hospital B & Hospital C & Hospital D & Hospital E \\
\hline Ala psiquiátrica & & 1 & & & \\
\hline Berçário & 1 & 1 & 1 & & 1 \\
\hline Sala de cirurgia & 2 & 2 & 2 & 2 & 2 \\
\hline Corredor & 3 & 3 & 4 & 3 & 4 \\
\hline Cozinha & 1 & 2 & 1 & 1 & 1 \\
\hline Copa & & & & & 1 \\
\hline Enfermaria & 2 & 2 & 2 & 2 & 1 \\
\hline Esterilização & & & & 1 & \\
\hline Expurgo & 3 & 3 & 4 & 3 & 3 \\
\hline Lavanderia & 1 & 1 & 1 & 1 & \\
\hline Padaria & 1 & & & & \\
\hline Pediatria & 2 & & & 2 & 1 \\
\hline Posto de enfermagem & & 1 & & & 1 \\
\hline Recuperação & 1 & 1 & 1 & 1 & 1 \\
\hline Refeitório & & 1 & 1 & 1 & \\
\hline Sala de espera & & & & & 1 \\
\hline Sala de parto & 1 & 1 & 1 & 1 & 1 \\
\hline Sala de residência & & & & & 1 \\
\hline UTI pediátrica & & & & 1 & 1 \\
\hline UTI & 1 & 1 & 1 & 1 & 1 \\
\hline Total & 19 & 20 & 19 & 20 & 21 \\
\hline
\end{tabular}




\section{Análise de dados}

A frequência de ocorrência de formigas foi obtida pela porcentagem dos pontos amostrais em que determinada espécie foi encontrada em relação ao total de pontos amostrais onde foram coletadas formigas (Silveira Neto et al., 1976). Na análise de correlação buscou-se estabelecer o grau de associação linear entre temperatura média mensal em relação ao índice de ocorrência de formigas no determinado mês, assim como entre o número de leitos de cada hospital com o índice de ocorrência de formigas no mesmo. Os dados relativos às temperaturas médias do Município de Pelotas, nos anos 2008 e 2009, foram fornecidos pela Estação Agroclimatológica da UFPel.

\section{RESULTADOS E DISCUSSÃO}

\section{Ocorrência de formigas}

Durante a realização do trabalho foram coletadas sete espécies de formigas: Tetramorium bicarinatum (Nylander, 1846), Pheidole nubila (EMERY, 1906), Pheidole spininodis MAYr, 1887, S. saevissima, Pheidole sp. 1, P. fulva e Cardiocondyla emeryi Forel, 1881, a última registrada pela primeira vez em um hospital. Lise et al. (2006) encontraram o mesmo número de espécies ao avaliar dois hospitais em Chapecó, SC, enquanto Moreiraet al. (2005) coletaram quatro espécies em três instituições de Campos dos Goytacazes, RJ e Costa et al. (2006) verificaram a ocorrência de três espécies no Hospital Escola de Uberaba, MG. Durante a primeira estação do estudo, S. saevissima não foi atraída para a isca de mel, minhoca e açúcar, apesar de ter sido coletada manualmente. Dessa forma, foi oferecida, também, a isca de sardinha a partir da segunda estação.

As formigas estiveram presentes em, pelo menos, uma estação, em 13 setores dentre os 99 amostrados, perfazendo um índice total de ocorrência de 13,1\%. O hospital E apresentou o maior número de setores (quatro) com ocorrência de formigas, enquanto o hospital B teve somente um setor (Tabela 2). Tais resultados diferem de outros levantamentos em hospitais brasileiros, onde a ocorrência de formigas foi verificada em número expressivo de setores (ZARZUEla et al., 2002; TANAKA et al., 2007; PESQUeRO et al., 2008; FONSECA et al., 2010).

A correlação entre o número de leitos de cada hospital e oíndice de ocorrência não foi significativa $(p=0,091)$, indicando que o tamanho dos hospitais não teve relação direta com a presença de formigas. Como o número de leitos está diretamente relacionado com a circulação de pessoas em um hospital, os dados obtidos diferem de outros trabalhos que encontraram maior índice de ocorrência de formi- gas em hospitais com maior circulação de pessoas (Lise et al., 2006; Вicho et al., 2007). Cabe ressaltar que, em relação ao tipo de hospital estudado, os dois hospitais particulares, $\mathrm{B}$ e $\mathrm{C}$, apresentaram o menor índice de ocorrência de formigas, sugerindo que nesse tipo de instituição pode haver menor tendência à ocorrência desses insetos. Entretanto, posteriores estudos são necessários para melhor compreender as causas.

Para determinar a frequencia das formigas, foram consideradas as oito coletas realizadas durante os dois anos de levantamento nos 99 setores dos hospitais, totalizando 792 pontos amostrais, dos quais 33 registraram a presença de formigas. Nos hospitais A e C, T. bicarinatum e $P$. spininodis foram, respectivamente, as espécies mais frequentes, enquanto no hospital E, P. nubila e S. saevissima foram as formigas mais frequentes. Por sua vez, nos hospitais B e D, P. nubila e T. bicarinatum foram, respectivamente, as únicas formigas verificadas (Tabela 3).

T. bicarinatum, uma espécie exótica, com distribuição mundial e de provável origem do sudeste asiático, apresenta especial interesse para a saúde pública por possuir a capacidade de ferroar (BOLTON, 1979). Essa formiga foi coletada na sala de recreação pediátrica em dois hospitais, além de um quarto de maternidade, inclusive sendo observada ferroando um bebê (observação pessoal), evidenciando um potencial perigo para crianças. Mesmo tendo sido encontrada emapenas 3,3\% dos domicílios de Pelotas (SILVA; LoECK, 1999) e não figurar entre as espécies comumente coletadas nesses ambientes, essa formiga parece ter se adaptado a ambientes altamente restritivos, a exemplo dos hospitais.

S. saevissima é uma espécie amplamente distribuída no Brasil e possui importância médica devido às suas dolorosas ferroadas (SILVA; LOECK, 1999; Moreira et al., 2005; Lise et al., 2006), entretanto, pouco se sabe sobre sua biologia, fato atribuído a existência de confusões taxonômicas de longa data no gênero (TRAGER, 1991; GUSMÃo et al., 2010). As informações sobre o grupo de espécies "S. saevissima", formigas polimórficas conhecidas como "lava-pés" ou "formigas-fogo", no qual essa espécie foi classificada (PITTs et al., 2005), indicam que o veneno tende a aumentar de volume proporcionalmente ao tamanho da casta (LAI et al., 2009) e pode causar prurido, reações alérgicas e até mesmo choque anafilático (KiPPER et al., 1998; FERNÁNDEZ-MELÉNDEZ et al., 2007), o que lhe confere grande importância em relação à saúde pública.

A ocorrência de espécies do gênero Pheidole em hospitais brasileiros tem sido amplamente documentada (Fowler et al., 1993; BARRos et al., 2006; COSTA et al., 2006; FONSECA et al., 2010), inclusive na condição de unicolonial e dominante (Pesquero et al., 2008), mas as dificuldades taxonômicas inerentes ao grupo 
(WILSON, 2003) têm dificultado a identificação em nível específico, não permitindo inferências mais precisas sobre os indivíduos coletados pelos diferentes autores, ou mesmo a obtenção de informações sobre sua biologia. A formiga P. nubila, a qual ocorreu em quatro hospitais, sempre localizada somente em um ponto amostral em cada instituição, apenas no verão e na primavera, despertou interesse pela ampla distribuição. Em três hospitais, foi coletada em corredores e noutro numa sala de espera da UTI, sendo que no corredor do hospital A o ninho situava-se no ambiente interno, atrás do rodapé, enos demais no exterior. Considerando o unicolonialis- mo de formigas do gênero e seu comportamento de recrutamento massal de operárias (WILSON, 2003), somado ao hábito dos acompanhantes e visitantes dos enfermos frequentemente disponibilizarem restos de alimentos dentro de hospitais (ZARZuELA et al., 2002), existe a possibilidade desses indivíduos infestarem áreas de risco.

A ocorrência de Camponotus spp. é frequentemente relacionada a problemas estruturais nas edificações (Fowler et al., 1993; BUENo; FowlER, 1994). Sua ausência provavelmente está relacionada com as boas condições de conservação das edificações dos hospitais estudados.

Tabela 2 - Relação das cepas bacterianas isoladas de formigas coletadas em cinco hospitais do Município de Pelotas, RS.

\begin{tabular}{|c|c|c|c|c|}
\hline Setor & Estação/Ano & Hosp. & Formiga & Bactérias \\
\hline Posto enfermagem & Verão/2008 & $\mathrm{E}$ & C. emeryi & Staphylococcus saprophyticus \\
\hline Corredor & Verão/2008 & $\mathrm{C}$ & P. fulva & * \\
\hline Corredor** & Verão/2008 & A & P. nubila & nenhuma \\
\hline Corredor & Verão/2008 & B & P. nubila & * \\
\hline Corredor & Verão/2008 & C & P. nubila & Staphylococcus epidermidis e Enterobactérias \\
\hline Sala de espera & Verão/2008 & E & P. nubila & Enterobactérias \\
\hline Sala espera** & Verão/2008 & $\mathrm{C}$ & P. spininodis & S. epidermidis e Pseudomonas spp. \\
\hline Pediatria & Verão/2008 & A & Pheidole sp. & Enterobactérias \\
\hline Lavanderia & Verão/2008 & A & S. saevissima & S. epidermidis e Staphylococcus spp. \\
\hline Corredor & Verão/2008 & $\mathrm{E}$ & S. saevissima & Staphylococcus spp. e Pseudomonas aeruginosa \\
\hline Lavanderia & Verão/2008 & A & T. bicarinatum & * \\
\hline Pediatria & Verão/2008 & A & T. bicarinatum & Enterobactérias \\
\hline Expurgo & Verão/2008 & $\mathrm{D}$ & T. bicarinatum & S. epidermidise Staphylococcus spp.e Enterobactérias \\
\hline Corredor & Outono/2008 & $\mathrm{C}$ & P. fulva & * \\
\hline Sala espera** & Outono/2008 & $\mathrm{C}$ & P. spininodis & nenhuma \\
\hline Pediatria & Outono/2008 & A & Pheidole sp. & nenhuma \\
\hline Sala espera** & Inverno/2008 & $\mathrm{C}$ & P. spininodis & Enterobactérias \\
\hline Pediatria & Inverno/2008 & A & Pheidole sp. & S. epidermidis, Staphylococcus spp. e Enterobactérias \\
\hline Corredor** & Primavera/2008 & A & P. nubila & Enterobactérias \\
\hline Corredor & Primavera/2008 & $\mathrm{C}$ & P. nubila & S. epidermidis e Enterobactérias \\
\hline Sala espera** & Primavera/2008 & $\mathrm{C}$ & P. spininodis & $\begin{array}{l}\text { S. epidermidis, S. saprophyticus, Staphylococcus spp. } \\
\text { e Enterobactérias }\end{array}$ \\
\hline Expurgo & Primavera/2008 & $\mathrm{D}$ & T. bicarinatum & S.epidermidis, Staphylococcus spp.e Enterobactérias \\
\hline Sala residência & Verão/2009 & $\mathrm{E}$ & S. saevissima & S. epidermidis, Pseudomonas spp.e Enterobactérias \\
\hline Pediatria & Verão/2009 & A & T.bicarinatum & $\begin{array}{l}\text { S. saprophyticus, Enterobactérias, } P \text {. fluorescens e } \\
P \text {. putida }\end{array}$ \\
\hline Lavanderia & Verão/2009 & A & T. bicarinatum & $\begin{array}{l}\text { S. epidermidis, S. saprophyticus, Enterobactérias, } P \text {. } \\
\text { fluorescens e } P \text {. putida }\end{array}$ \\
\hline Expurgo & Verão/2009 & $\mathrm{D}$ & T. bicarinatum & S. epidermidis, S. saprophyticus e Staphylococcus spp. \\
\hline Pediatria & Verão/2009 & $\mathrm{D}$ & T. bicarinatum & S. saprophyticus e Enterobactérias \\
\hline Quarto maternidade & Verão/2009 & $\mathrm{D}$ & T. bicarinatum & $\begin{array}{l}\text { S. epidermidis, S. saprophyticus, Staphylococcus spp. } \\
\text { e Enterobactérias }\end{array}$ \\
\hline Sala espera** & Outono/2009 & $\mathrm{C}$ & P. spininodis & S. saprophyticus, P. fluorescens e Pseudomonas putida \\
\hline Quarto maternidade & Outono/2009 & $\mathrm{D}$ & T. bicarinatum & nenhuma \\
\hline Sala espera** & Inverno/2009 & $\mathrm{C}$ & P. spininodis & S. epidermidis, S. saprophyticus e Enterobactérias \\
\hline Corredor & Primavera/09 & B & P. nubila & * \\
\hline Sala espera & Primavera/2009 & $\mathrm{E}$ & P. nubila & Staphylococcus spp. e Pseudomonas fluorescens \\
\hline
\end{tabular}

* Não foi possível realizar a coleta asséptica.

** Ninho localizado no interior da edificação. 


\section{Distribuição e sazonalidade}

Não foram encontradas formigas em locais de granderisco para pacientes imunodeprimidos, como: UTI's, centros cirúrgicos, salas de parto ou enfermarias, nem em setores de processamento de alimentos, mas sim em locais de acesso, como salas de espera, corredores e salas de expurgo (Tabela 2). No entanto, tratando-se de insetos com grande capacidade de deslocamento à procura de alimentos ou locais para nidificação (BUENO; CAMPOS-FARINHA, 1998), existe a possibilidade de infestação de outros setores caso medidas preventivas não sejam adotadas.

Com relação à sazonalidade, verificou-se maior ocorrência de formigas durante o período do verão $(57,6 \%)$ e menor no inverno $(9,1 \%)$, ocorrendo correlação entre a temperatura média do mês de coleta e o índice de ocorrência de formigas nele $(p=0.54)$ (Fig. 1). Apesar das coletas terem ocorrido em ambientes internos, onde a temperatura não sofre variações tão acentuadas como no exterior das edificações, os ninhos da maioria das espécies coletadas localizavam-sena área externa dos prédios, com exceção de um ponto amostral de P. nubila no hospital A e outro de $P$. spininodis no hospital C (Tabela 2). Dessa forma, os espécimes podem ter sofrido maior influência das condições climáticas adversas do que o esperado com relação às coletas de formigas em hospitais.

\section{Bactérias patogênicas}

Das 28 amostras de formigas coletadas assepticamente, 25(89,3\%) apresentaram bactérias patogênicas, número muito próximo ao encontrado por Lise et al. (2006) (85,7\%) e PEREIRA; UENO (2008) (92.9\%), ao passo que RodovalHoetal. (2007) encontraram menor índice de contaminação (33,3\%). As Enterobactérias foram encontradas em maior número de amostras $(60,7 \%)$, seguidas por S. epidermidis (46.4\%), S. saprophyticus e Staphylococcus spp.(ECN) (32.1\%) (Fig. 2)Praticamente qualquer doença infecciosa pode ser causada por Enterobactérias, sendo que a contaminação a partir de procedimentos invasivos, como cateterismo, broncoscopia, colposcopia ou biópsias cirúrgicas, tornamos pacientesimunocomprometidosaltamentesuscetíveis a esses patógenos (Koneman et al., 2001). A associação entre Enterobactérias e formigas tem sido observada em alguns hospitais no Brasil, o que sempre é considerado risco para os pacientes internados (MOREIRA et al., 2005; PereIRA; Ueno, 2008; PESQUero et al., 2008).

As infecções produzidas por S.epidermidis incluem endocardite de válvulas cardíacas naturais e proteicas, infecções produzidas por cateteres endovenosos, peritonite associada a cateter para diálise peritoneal, bacteremia, infecções de feridas, infecções de próteses e infecções de vias urinarias (KonEMAN et al., 2001). Costa etal. (2006) verificaram a associação dessas bactérias com T. melanocephalum na enfermaria pediátrica em um hospital de Campos dos Goytacazes, RJ. Os mesmos autores também isolaram $S$. saprophyticus dessa espécie de formiga em uma UTI pediátrica, que se caracteriza por causar infecções urinárias agudas, sobretudo em mulheres jovens, saudáveis e sexualmente ativas. Este micro-organismo também foi relacionado por TRABULSI (1991) como causa de uretrite em homens e mulheres e infecções das vias urinárias associadas com sondas.

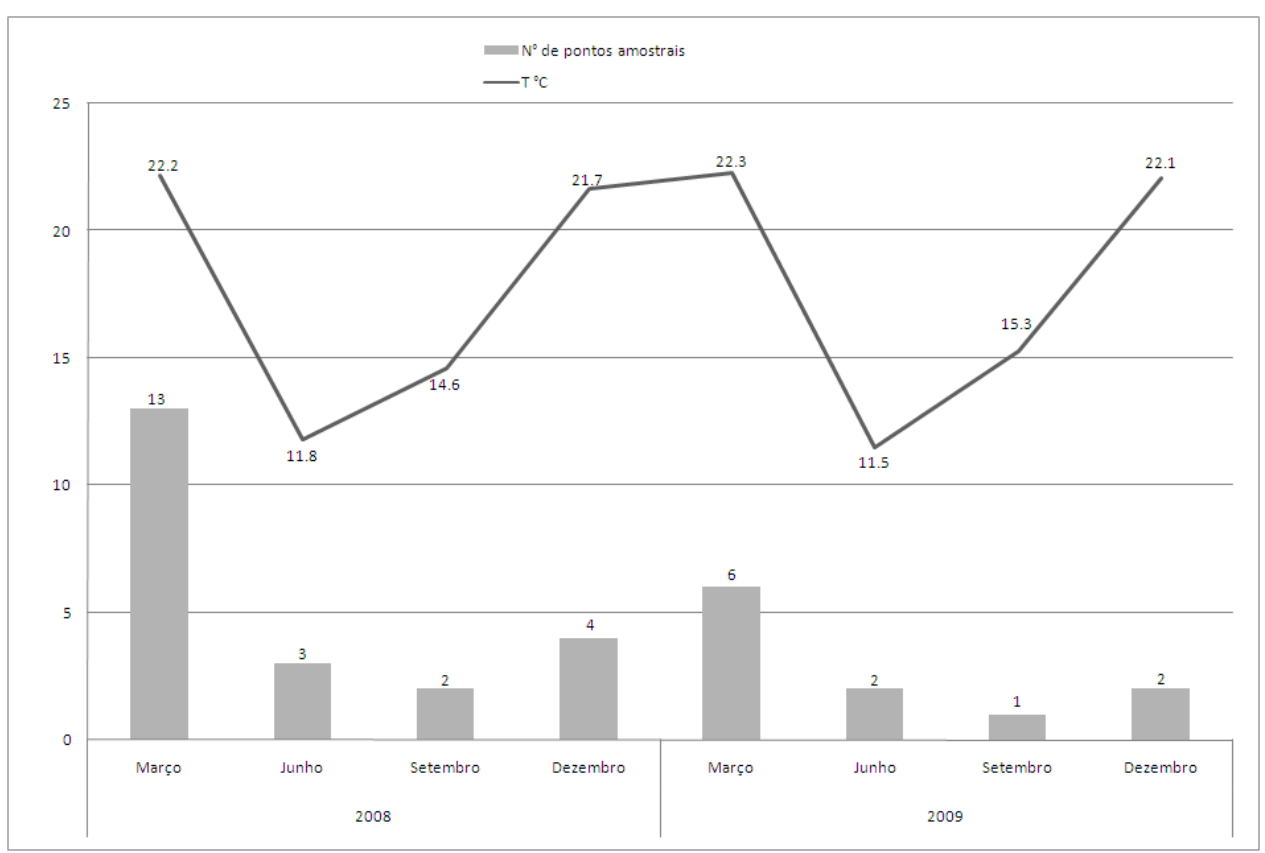

Fig. 1 - Correlação entre a temperatura média dos meses de coleta e o número de pontos amostrais com presença de formigas em cinco hospitais do Município de Pelotas, RS, durante os anos de 2008 e 2009. 


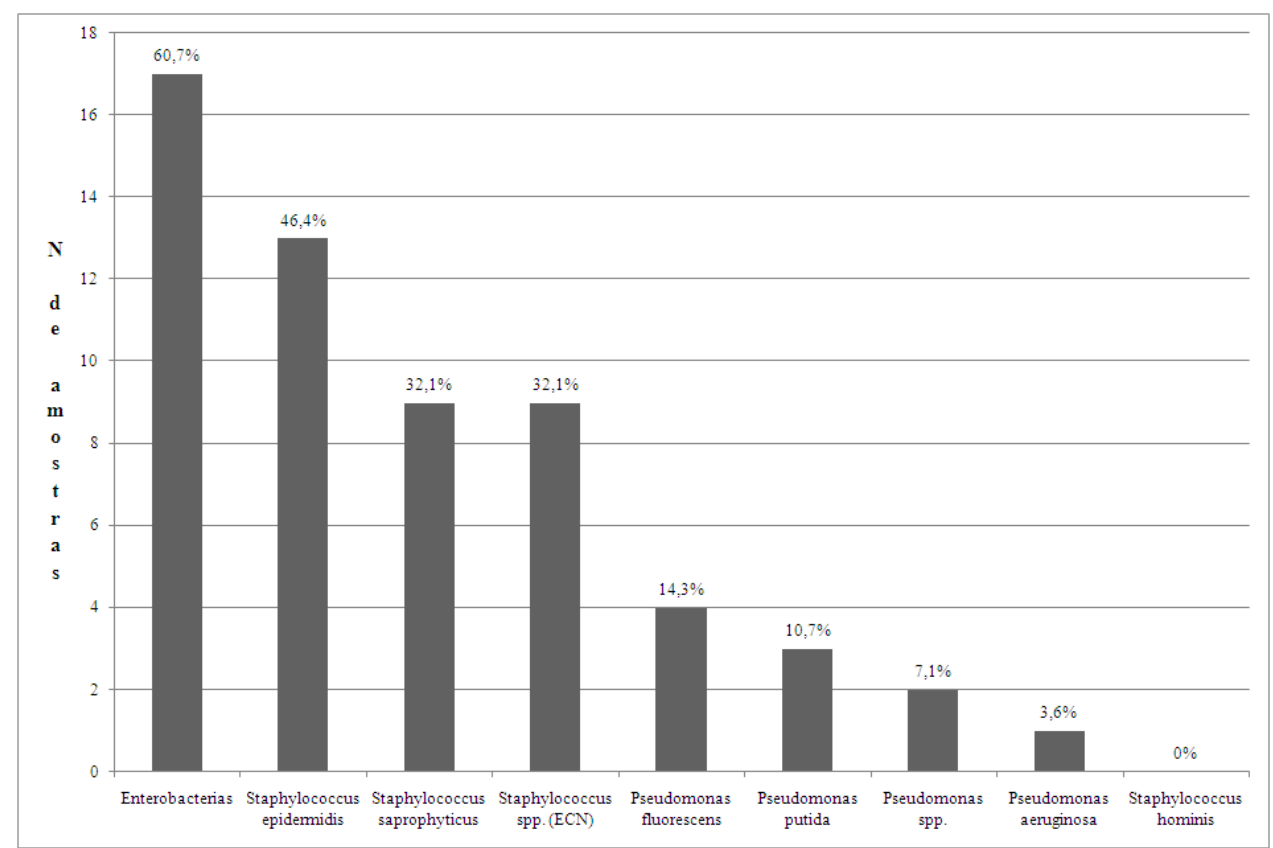

Fig. 2 - Número de amostras nas quais as bactérias foram isoladas em cinco hospitais de Pelotas, RS nos anos de 2008 e 2009. O número acima das colunas indica a porcentagem de ocorrência de cada espécie em relação ao número total de amostras em que foram isoladas bactérias.

Tabela 3 - Número de pontos amostrais e frequencia de ocorrência das sete espécies de formigas coletadas durante os anos de 2008 e 2009, em cinco hospitais do Município de Pelotas, RS.

\begin{tabular}{|c|c|c|c|c|c|}
\hline \multirow{2}{*}{ Formiga } & \multicolumn{5}{|c|}{ Hospital } \\
\hline & A & $\mathrm{B}$ & $\mathrm{C}$ & $\mathrm{D}$ & $\mathrm{E}$ \\
\hline Cardiocondyla emeryi & & & & & $1(0,2)$ \\
\hline Paratrechina fulva & & & $2(0,2)$ & & \\
\hline Pheidole sp. 1 & $3(0,3)$ & & & & \\
\hline Pheidole nubila & $2(0,2)$ & $2(1)$ & $2(0,2)$ & & $2(0,4)$ \\
\hline Pheidole spininodis & & & $6(0,6)$ & & \\
\hline Solenopsis saevissima & $1(0,1)$ & & & & $2(0,4)$ \\
\hline Tetramorium bicarinatum & $4(0,4)$ & & & $6(1)$ & \\
\hline Total & 10 & 2 & 10 & 6 & 5 \\
\hline
\end{tabular}

Pseudomonas aeruginosa éfrequentemente isolada de amostras clínicas, causando infecção, geralmente associada a sítios com tendência ao acúmulo de umidade, como traqueostomias, cateteres permanentes, queimaduras eferidas exsudativas (Bodey et al.,1983). $P$. fluorescens e $P$. putida são encontradas em águas e solos, compondo a microbiota natural da faringe (Koneman et al., 2001). Pode ocorrer a produção de septicemia por $P$. putida relacionada com cateter em pacientes com câncer (ANAISSIE et al., 1987) e artrite séptica (MACFARLANE et al., 1991). O fato dessas bactérias estarem associadas com formigas aumenta seu potencial de contaminação dentro de hospitais.

Os resultados microbiológicos evidenciaram que, com exceção das espécies C. emeryi e P. fulva, que foram pouco frequentes, as demais estavam contaminadas com Enterobactérias e S. epidermidis em pelo menos uma das coletas (Tabela 2). Além disso, é importante ressaltar que, com exceção do hospital B, no qual não se conseguiu realizar a coleta asséptica, nos demais hospitais foram encontradas bactérias patogênicas sobre as formigas.

O número de espécies bacterianas isoladas por amostra de formiga variou de zero a cinco ( $T$. bicarinatum na lavanderia do hospital $\mathrm{A}$ ), sendo que das 28 amostras testadas para a presença de bactérias, 20 apresentaram a ocorrência de mais de uma espécie (Tabela 2).

Com base nos resultados obtidos, pode-se concluir que as formigas encontradas nos hospitais estudados representam riscos à saúde por transportar patógenos reconhecidamente causadoras de infecções nosocomiais. Apesar de estarem presentes durante todo o ano, devem receber especial atenção na estação de verão, quando apresentam maior atividade forrageira. Deve ser considerada ainda 
que a maioria das formigas encontradas nidifica na área externa dos hospitais, vindo a forragear dentro das instalações, indicando que maior atenção deve ser dispensada a esses ambientes por parte dos agentes de controle.

\section{AGRADECIMENTOS}

Aos administradores e funcionários dos hospitais avaliados, pelo interesse e colaboração durante a realização do trabalho. À Natalia Camacho, pelo auxílio nas avaliações microbiológicas. A Rodrigo Feitosa e Carlos Roberto Brandão, por oportunizarem e auxiliarem a visitação da coleção mirmecológica do MZUSP. Ao CNPq, pelo aporte financeiro, e à CAPES, pela concessão de bolsa de estudos.

\section{REFERÊNCIAS}

AGOSTI, D.; JOHNSON, N.F. (Ed.). World Wide Web electronic publication. 2005. Disponível em: <http:// www.antbase.org>. Acesso em: 22 jan. 2010.

ANAISSIE, E.; FAINSTEIN, V.; MILLER, P.; KASSAMALI, H.; PITLIK, S.; BODEY, G.P.; ROLSTON, K. Pseudomonas putida: newly recognized pathogen in patients with cancer. The American Journal of Medicine. v.82, p.1191-1194, 1987.

BARROS, R.A.M.; CAMPOS-FARINHA, A.E.C.; PREZOTO, F. Ocorrência, comportamento e vetoração de fungos por formigas no Hospital da Universidade Federal de Juiz de Fora, Minas Gerais. Revista Brasileira de Zoociências. n.8, p.217, 2006.

BICHO, C.L.; BRANCÃO, M.L.C.; PIRES, S.M. Mirmecofauna (Hymenoptera, Formicidae) em hospitais e postos de saúde no município de Bagé, RS. Arquivos do Instituto Biológico, São Paulo, v.74, n.4, p.373-377, 2007.

BLATT, J.M.; MIRANDA, M.C. Perfil dos microrganismos causadores de infecções do trato urinário em pacientes internados. Revista Panamericana de Infectologia, v.7, p.10-14, 2005.

BODEY, G.P.; BOLIVAR, R.; FAINSTEIN, V.; JADEJA, L. Infections caused by Pseudomonas aeruginosa. Reviews of Infectious Diseases. v.5, p.279-313, 1983.

BOLTON, B. The ant tribe Tetramoriini (Hymenoptera: Formicidae). The genus Tetramorium Mayr in the Malagasy region and in the New World. Bulletin of the British Museum (Natural History) Entomology Series, v.38, p.129-181, 1979.

BUENO, O.C.; FOWLER, H.G. Exotic ants and native ant fauna of Brazilian hospitals. In: WILLIAMS, D.F. (Ed.). Exotic ants: biology, impact, and control of introduced species. Boulder: West View Press, 1994. 332p.
BUENO, O.C.; CAMPOS-FARINHA, A.E. Formigas urbanas: comportamento das espécies que invadem as cidades brasileiras. Vetores \& Pragas, n.2, p.13-16, 1998.

CAMPOS-FARINHA, A.E.C.; BUENO, O.C.; CAMPOS, M.C.G.; KATO, L.M. As formigas urbanas no Brasil: retrospecto. O Biológico, São Paulo, v.64, n.2, p.129-133, 2002.

COSTA, S.B.; PELLI, G.P.; CARVALHO, P.; OLIVEIRA, A.G.; SILVA, P.R.; TEIXEIRA M.M.; MARTINS, E.; TERRA, A.P.S.; RESENDE, E.M.; OLIVEIRA, C.C.H.B.; MORAIS, C.A. Formigas como vetores mecânicos de microorganismos no Hospital Escola da Universidade Federal do triângulo Mineiro. Revista da Sociedade Brasileira de Medicina Tropical, v.39, n.6, p.527-529, 2006.

FERNÁNDEZ, F. Introducción a las hormigas de la región neotropical. Bogotá: Instituto de investigación de recursos biológicos Alexander von Humboldt, 2003. 418p.

FERNÁNDEZ-MELÉNDEZ, S.; MIRANDA, A.; GARCÍA-GONZÁLEZ, J.J.; BARBER, D.; LOMBARDERO, M. Anaphylaxis caused by Imported Red Fire Ant stings in Málaga, Spain. Journal of Investigational Allergology and Clinical Immunology, v.17, n.1, p.48-49, 2007.

FONSECA, A.R.; BATISTA, D.R.; AMARAL, D.P.; CAMPOS, R.B.F.; SILVA, C.G. Formigas (Hymenoptera: Formicidae) urbanas em um hospital no município de Luz, Estado de Minas Gerais. Acta Scientiarum, v.32, n.1, p.29-34, 2010.

FOWLER, H.G.; BUENO, O.C.; SADATSUNE, T.; MONTELLI, A.C. Ants as potential vectors of pathogens in hospitals in the State of São Paulo, Brasil. Insect Science and its Application, v.14, n.3, p.367-370, 1993.

GUILARDE, A.O.; TURCHI, M.D.; MARTELLI, C.M.T.; PRIMO, M.G.B.; BATISTA, L.J.A. Bacteremias em pacientes internados em hospital universitário. Revista da Associação Médica Brasileira, v.53, p.34-38, 2007.

GUSMAO, F.A. ; HARAKAVA, R.; CAMPOS, A.E.C. Fire-Ants of the Solenopsis saevissima Species-Group Nesting in Parks in the City of São Paulo: Identification based on mtDNA Sequences and Morpholocial Characters. Sociobiology, v.56, p.353-362, 2010.

KIPPER, D.J.; SALDANHA, M.O.; TESSARO, L.; LANÇA, E.A.; GARCIA, P.C. Reações anafiláticas a picadas de formigas. Jornal de Pediatria, v.74, n.3, p.243-246, 1998.

KONEMAN, E.W.; ALLEN, S.D.; JANDA, W.M.; SCHRECKENBERGER, P.C.; WINN JUNIOR. W.C. Diagnóstico microbiológico. São Paulo: Medsi, 2001. 1466p.

LAI, L.C.; HUA, K.H.; YANG, C.C.; HUANG, R.N.; WU, W.J. Secretion profiles of venom alkaloids in Solenopsis geminata (Hymenoptera: Formicidae) in Taiwan. Environmental Entomology, v.38, n.3, p.879-84, 2009. 
LISE, F.; GARCIA. F.R.M.; LUTINSKI, J.A. Associação entre formigas (Hymenoptera: Formicidae) e bactérias em hospitais de Santa Catarina. Revista da Sociedade Brasileira de Medicina Tropical, v.39, n.6, p.532-526, 2006.

MacFARLANE, L.; OPPENHEIM, B.A.; LORRIGAN, P. Septicaemia and septic artritis due to Pseudomonas putida in a neutropenic patient. Journal of Infectology, v.23, p.346-347, 1991.

MOREIRA, D.D.O.; MORAIS, V.; VIEIRA-DA-MOTTA, O.; CAMPOS-FARINHA, A.E.C.; TONHASCA JU-

NIOR, A. Ants as carriers of antibiotic-resistant bacteria in hospitals. Neotropical Entomology. v.34, n.6, p.9991006, 2005.

MORENO, J.A. Clima do Rio Grande do Sul. Porto Alegre: Secretaria da Agricultura, 1961. 42p.

PESQUERO, M.A.; ELIAS FILHO, J.; CARNEIRO, L.C.; FEITOSA, S.B.; OLIVEIRA, M.A.C.; QUINTANA, R.C.

Formigas em Ambiente Hospitalar e seu Potencial como Transmissoras de Bactérias. Neotropical Entomology, v.37, n.4, p.472-477, 2008.

PEREIRA, R.S.; UENO, M. Formigas como veiculadoras de microrganismos em ambiente hospitalar. Revista da Sociedade Brasileira de Medicina Tropical, v.41, n.5, p.492495, 2008.

PITTS, J.P.; McHUGH, J.V.; ROSS, K.G. Cladistic analysis of the fire ants of the Solenopsis saevissima species-group (Hymenoptera: Formicidae). Zoologica Scripta, v.34, n.5, p. 493-505, 2005.

QUIRINO, N.E.P.S. Controle da água e vetores. In: COUTO, R.C.; PEDROSA, T.M.G.; NOGUEIRA, J.M. (Ed.). Infecção hospitalar: epidemiologia e controle. São Paulo: MEDSI, 1997. 530p.

RODOVALHO, C.M.; SANTOS, A.L.; MARCOLINO, M.T.; BONETTI, A.M.; BRANDEBURGO, M.A.M.

Urban ants and transportation of nosocomial bacteria. Neotropical Entomology, v.36, n.3, p.454-458, 2007.
SEIFERT, B. The ant genus cardiocondyla (Insects: Hymenoptera: Formicidae) - a taxonomic revision of the C. elegans, C. bulgarica, C. batesii, C. nuda, C.

shuckardi, C. stambuloffii, C. wroughtonii, C. emeryi and C. minutior species groups. Annalen des Naturhistorischen Museums in Wien, v.104, p.203-338, 2003.

SILVA, E.J.E.; LOECK, A.E. Ocorrência de formigas domiciliares (Hymenoptera: Formicidae) em Pelotas, RS. Revista Brasileira de Agrociência, v.5, n.3, p.220-224, 1999.

SILVEIRA NETO, S.; NAKANO, O; BARDIN, D.; VILA NOVA, N.A. Manual de ecologia de insetos. São Paulo: Agronômica Ceres, 1976. 420p.

SNEATH, P.H.A.; MAIR, N.S.; SHARPE, M.E.; HOLT, J.G. Bergey's Manual of Systematic Bacteriology. Baltimore: Williams \& Wilkins, 1986. v.2, p.1104-1599.

TANAKA, I.I.; VIGGIANI, A.M.F.S.; PERSON, O.C. Bacterias veiculadas por formigas em ambiente hospitalar. Arquivos Médicos do ABC, v.32, n.2, p.60-3, 2007.

TRABULSI, L.R. Microbiologia. Rio de Janeiro: Editora Atheneu, 1991. 720p.

TRAGER, J.C. A revision of the fire ants, Solenopsis geminata group (Hymenoptera: Formicidae: Myrmicinae). Journal of the New York Entomological Society, v.99, p.141198, 1991.

WILSON, E.O. (Ed). Pheidole in the new world: a dominant, hyperdiverse ant genus. Cambridge: Harvard University Press, 2003. 794p.

ZARZUELA, M.F.M.; RIBEIRO, M.C.C.; CAMPOSFARINHA, A.E.C. Distribuição de formigas urbanas em um hospital da região sudeste do Brasil. Arquivos do Instituto Biológico, São Paulo, v.69, n.1, p.85-87, 2002.

Recebido em $1 / 2 / 10$

Aceito em 17/2/11 